\title{
Referencias y equivalencias del pronombre on francés en el español
}

\author{
KOFFI YAO \\ Universidad FHB de Abiyán \\ Costa de Marfil
}

\begin{abstract}
Resumen
Los errores causados por la dificultad de aprehender los contrastes entre el pronombre indefinido francés on y sus equivalencias en español durante el aprendizaje-enseñanza de alumnos francófonos constituye el objeto principal de este estudio. Se proponen otros recursos teóricos frente a criterios convencionales formulados en los manuales clásicos de gramática. Asimismo, se comprueba que el estudio fragmentado del on, restringido a enunciados aislados, resulta útil pero muy limitado para determinar las propiedades gramaticales de focalización referencial, que permiten, a su vez, establecer las correspondientes equivalencias en español. En consecuencia, siguiendo una perspectiva contrastiva basada en la experiencia bilingüe francés-español en la enseñanza, se examina dicho pronombre en el marco de la pragmática como recurso teórico (aplicado al análisis de un corpus recogido en actos comunicativos entre españoles y otros extraídos de algunos manuales de gramática) que ha probado su eficiencia mediante resultados muy concluyentes.
\end{abstract}

Palabras claves: pronombre francés on, pronombre indefinido, focalización, equivalencias, pragmática

\section{Abstract}

The errors carried out by the contrast between the French indefinite on and its correspondences in Spanish in teaching and learning process is the main object of this study, in which other theoretical means are submitted against convencional criteria in classical grammar books. Likewise, it's noticed that the restrictive analysis of this pronoun reduced to isolated sentences is useful but show limits to determine gramatical 
properties of referencial focus that allow the representation of the correspondent equivalences in Spanish. Consequently, on the base of contrastive approach on bilingual French and Spanish teaching, this study proposes the criteria of pragmatic analysis, applying this theoretical mean to analyse a corpus registered in communicative acts and some grammar books, with efficiency and conclusive results.

Key words: french pronoun on, indefinite pronoun, focus, equivalences, pragmatics

\section{Introducción}

$\mathrm{E}$ sta propuesta analiza el pronombre indefinido on del francés cuyos referentes y equivalencias son, con frecuencia, objeto de alguna que otra confusión observada entre francófonos que hablan o aprenden el español. En ocasiones, ocurre que la percepción y la interpretación que atribuyen al indefinido on en el francés no se corresponde con el concepto que tienen los españoles. La discordancia entre ambos representa la problemática a partir de la que surge este análisis que trata el conjunto de errores que cometen algunos francófonos, y nuestros alumnos ${ }^{1}$ en especial, durante el proceso de ensenanza-aprendizaje de este pronombre en el español como L2.

El estudio se fundamenta en la hipótesis según la cual las afinidades existentes entre estas lenguas neolatinas predisponen a algunos aprendientes francófonos a construir unas equivalencias tácitas y preestablecidas entre ellas. En otras palabras, al ser lenguas genéticamente emparentadas, se considera implícitamente que el indefinido es o funciona igual en ambos sistemas. Pero este planteamiento es muy equivocado $\mathrm{y}$, además, favorece ciertas interferencias ${ }^{2}$, en términos de influencia y violación de las normas de la lengua estudiada (L2).
En general, el fenómeno de transferencias, en el marco del estudio francés-español (Franco, 1990 y Quilis, 1986), genera múltiples problemas estructurales. Recordemos que la mayoría de los estudios históricos (Resnick, 2011; Anda Gutiérrez, 2004 y Aurelio González, 2006) han demostrado que el parentesco genético entre unas lenguas y otras no implica en sí ninguna equivalencia sistemática entre ellas. Esta realidad es comprobable en varios niveles gramaticales (Bouzet, 1974) ${ }^{3}$, incluido el pronombre, on, objeto de nuestro estudio.

Siguiendo sus características lexicosemánticas y funcionales, este elemento gramatical (Landragin y Noalig, 2014) puede considerarse una de las particularidades idiomáticas del francés; asimismo, la naturaleza heterogénea y ambigua de los referentes que es capaz de representar lo convierte en el componente más complejo del paradigma pronominal. Por su comportamiento particular, ha sido explorado por comparatistas como J. Borran (2010) y M. Borda (2013), y otros clásicos como J. Bouzet (1974), cuyo trabajo representa una importante contribución sobre el estudio de las correspondencias conceptuales y gramaticales de este pronombre indefinido on francés en el español. Sin embargo, entendemos que el enfoque estrictamente normativo y formal, tal y como lo proponen, podría 
resultar insuficiente, aunque representa, sin duda alguna, un punto de inflexión imprescindible para emprender cualquier reflexión de corte teórico y pedagógico, al igual que esta propuesta que se fundamenta también, y en lo esencial, en nuestra experiencia bilingüe español-francés en la docencia.

En general, según Luis Mendívil Giró (2009, p.41), las diferencias tipológicas y estructurales entre el francés y el español son importantes. El on como pronombre indefinido se usa tanto en el registro formal como informal para designar algún referente nominal, pero no tiene equivalencia exacta en español, el cual cuenta, además, con otras formas gramaticales: uno, se + verbo, etc., para expresar el indefinido. Ante esta divergencia y las consecuencias tanto conceptuales como estructurales que esta conlleva, corresponde proponer unos recursos teóricos que puedan ser de utilidad didáctica al alumnado quien necesita adquirir ciertas competencias con el fin de establecer con criterio cuándo, cómo y por qué emplear una forma $u$ otra del español frente al on francés. El análisis tendrá tres niveles relevantes:

a. Semántico (inclusión o de exclusión).

b. Morfosintáctico (formas o estructuras gramaticales).

c. Gramático-pragmático (implicatura y cooperación conversacional).

Para llevar a cabo esta tarea, nos servimos de un corpus restringido a la recopilación empírica de datos extraídos de ciertos actos comunicativos entre españoles ${ }^{4}$, además de examinar unas expresiones idiomáticas y algunos ejemplos procedentes de autoridades como M. Grévisse, A. Quilis ${ }^{5}$ y J. Bo$\operatorname{rran}^{6}$. Con este propósito, se persiguen dos objetivos precisos. Por un lado, se propone una aproximación teórica que permita identificar los referentes del on francés, así como las equivalencias en español. Esta misma herramienta proporcionará, por otro lado, una orientación pedagógica destinada a favorecer la asimilación de los complejos rasgos idiomáticos de este elemento gramatical. Los resultados que se expondrán demuestran la validez de la pragmática como recurso teórico que se asigna tanto a la focalización referencial, como a la representación adecuada de las correspondientes equivalencias de este indefinido on en español.

\section{Enfoque metodológico}

El estudio es esencialmente experimental además de basarse en la consulta de algunas fuentes bibliográficas que señalamos anteriormente. Sin embargo, el material recogido se examinará siguiendo la perspectiva de la lingüística de contrastes. Respecto a ello, C. Company (2005) indica que, en su origen, el método de contrastes lingüísticos tenía la finalidad de establecer la clasificación de lenguas, reconstituyendo así la realidad histórica con base en los parentescos genéticos que pudieran mantener entre ellas. Pero hoy en día, se aplica también a la comparación de lenguas y culturas diferentes con el fin de mejorar su enseñanza-aprendizaje, al tomar en consideración las dificultades con que los aprendientes tropiezan con unas y otras lenguas.

Asimismo, A. Yllera (2014) apunta que el método contrastivo se ha convertido en el campo predilecto de la lingüística aplicada a la enseñanza 
de lenguas, y su eficiencia queda ampliamente demostrada en casi todos los modelos y programas de educación bilingüe ${ }^{7}$. Se fundamenta en el principio teórico según el cual la lengua materna (L1) de los alumnos tiende interferir en la lengua que estudian (L2). A fin de resolver las dificultades de aprendizaje derivadas de esta proyección psicológica, este método aparece como una herramienta eficaz para la elaboración adecuada de los contenidos didácticos a partir de los contrastes establecidos en término de similitudes y diferencias estructurales. Lo usaremos para emprender este estudio del on francés y sus equivalencias en español.

\section{Definición de conceptos}

El on francés pertenece a la categoría de los pronombres indefinidos ${ }^{8}$, que se definen según la RAE como una clase de palabras que alude vagamente a personas o cosas o expresan una noción. En otros términos, puede decirse que el pronombre indefinido ${ }^{9}$ designa de forma genérica e indeterminada referentes anteriormente mencionados o no en el contexto. Atenidos a esta última consideración, destaca su carácter heteróclito e impreciso debido a la diversidad de referentes que abarca. Analizaremos en qué medida esta valoración se aplica al on que focaliza el interés de esta tarea. Esto lleva a efectuar diversas consultas en varias fuentes.

Maurice M. Grévisse (1994, p.1101), indica que on es un nominal que cuenta con diversas propiedades y desempeña casi siempre la función de sujeto:

a. Designa vagamente a cualquier persona, sea un individuo indeterminado, sea un grupo de personas sin precisar. Asimismo, tiene un carácter predominantemente heterogéneo y complejo.

b. Designa a una o varias personas más bien determinadas. En este caso, sustituye a cualquier pronombre personal (yo, tú, nosotros, vosotros él/ellos, ella/ellas). Por ejemplo: “On [vous, tu] est faché?”-1) ¿Está usted enfadado? (3. ${ }^{a}$ pers. sing.) -2) ¿Estás enfadado? (2. ${ }^{a}$ pers. sing.).

La gramática francesa de Espasa Calpe indica que el on es un pronombre indefinido que se utiliza con frecuencia en el lenguaje oral con el mismo sentido que la 1. ${ }^{\text {a }}$ persona del plural (nous). Pero también se emplea de manera coloquial cuando nos dirigimos a una persona (tu/tú) o a un conjunto de personas (vous/ vosotros). En este sentido, el registro adquiere un valor relevante en relación con los criterios en los que se fundamenta la identificación del referente y, en consecuencia, posibilitan estas alternativas de interpretación y de traducción del on al español.

Estas propuestas no difieren significativamente en el planteamiento, pero tampoco llegan a coincidir de forma absoluta. Esto se debe, sin duda alguna, a la complejidad idiomática que conlleva el on. Asimismo, la ausencia de equivalencias exactas entre las dos lenguas respecto al uso del on francés y las posibles formas gramaticales correspondientes en español obliga a examinarlo desde otras aproximaciones que puedan mejorar, de alguna manera, los conocimientos, esto es, la interpretación por parte de nuestros alumnos ${ }^{10}$.

Antes, notemos que los resultados que derivan de nuestras consultas permiten destacar, en términos sistemáticos y 
explícitos, los siguientes rasgos gramaticales y semánticos del on.

\subsection{Nivel morfosintáctico:}

Es un pronombre y, según hemos apuntado, puede sustituirse o permutar con los pronombres personales: je (yo), tu (tú), nous (nosotros/as), vous (vosotros/as) o usted/es, etc., sin perjudicar el semantismo de la oración en la que se usa. Cumple, por lo tanto, las mismas funciones que estos últimos.

Por pragmatismo, en la oración: on [vous, tu] est fâché? (Grévisse, 1994, p.1101), se sobreentiende que el on podría corresponder a los pronombre tu/tú, vous/ usted. Pero este empleo plantea un dilema en cuanto a la traducción al español. Equivaldría en español a: ¿estás enfadado? o ¿está usted enfadado? Sería interesante analizar hasta qué punto la sustitución del on por estos pronombres es correcta. Ya lo examinaremos más adelante.

De cualquier forma, se observa que on equivale en francés y en español a los pronombres personales que hemos indicado. Al margen de estos últimos, el español tiene otras formas gramaticales propias que corresponden también al on: uno, se + verbo, tercera persona plural, etc. Veamos los ejemplos siguientes:

c. Uno = on "Quand on se lave tous les jours (Bouzet, idem, p.280) - Cuando uno se lava todos los días".

d. $\mathrm{Se}+\mathrm{verbo}=$ on "On ne sait jamais" - Nunca se sabe.

e. Tercera persona plural = on "On parle français en France” (M. Borda, ibidem, p.140) - Hablan francés en Francia.

Pero la elección de cada una de estas variedades del indefinido está sujeta a otros factores semánticos y a la naturaleza gramatical del verbo ${ }^{11}$.

\subsection{Nivel semántico:}

\section{a. Indeterminado}

M. Grévisse (idem) se refiere al carácter ambiguo del on cuando designa vagamente a un individuo o a un grupo de individuos. También tiene carácter genérico y axiomático, como lo demuestra la expresión: "on n'est jamais mieux servi que par soi-même” (ibidem). En español, equivale a: Uno nunca está mejor servido que por sí mismo / Hazlo tú y serás bien servido.

\section{b. Determinado}

Cuando designa a una persona concreta. Por ejemplo: on [nous] déjeune demain ensemble? (Borda, 2013, p.140). En español equivale a: ¿Almorzamos [nosotros] juntos mañana? La referencia está claramente determinada: nosotros, que implica: tú y yo o vosotros(as) y nosotros(as), etc.

Se observa que on es polisémico. El mismo pronombre indefinido es indeterminado cuando designa vagamente a una persona o a un grupo de personas y es, al mismo tiempo, determinado cuando designa unas referencias concretas. Esta ambigüedad nos obliga a examinarlo siguiendo otros criterios.

\section{Valor incluyente / excluyente}

Mientras los demás pronombres tanto en francés como en español tienen unos valores referenciales claramente determinados, este pronombre on es tan complejo que resulta necesario interpretarlo antes de buscar sus equivalencias en español. Siguiendo 
los criterios de inclusión y la exclusión, se forman dos clases de pronombres:

\subsection{Valor incluyente de on:}

Se compone de todos los pronombres que implican la participación del je (yo). Es decir que on abarca:

$\underset{\text { nous }}{J e+t u ; j e+i l(s) / e l l e(s) ; j e+v o u s=}$

\subsection{Equivale en español a:}

yo + tú; yo + él; yo + vosotros(as); yo + él (ellos/as) $=$ nosotros(as)

\subsection{Valor excluyente de on:}

Excepto los pronombres je (yo), nous (nosotros), abarca todos los demás pronombres:

tu(tú), il(s)/ él(ellos); elle(s)/ella(s); vous (vosotros/as)

Se observa que je (yo) + je + tu (tú); je $+i l(s) / e l l e(s)$, (él/ellos, ella/ellas) y je (yo) + vous $=$ nous son incluyentes frente a $t u($ tú), il(s), (él/ellos), elle(s), ella(s), vous $($ vosotros/as, usted/es) = nous, que son excluyentes cuando no involucran el yo (je); en este caso on, se comporta como un pronombre "genérico", sin referente determinado.

En resumidas cuentas, on representa dos clases de pronombres. La primera es equivalente a: nous (nosotros), con valor incluyente; y la segunda es equivalente a vous (tú, vosotros/as, él/ ellos, usted/es) con valor excluyente. Estas propiedades muestran toda la complejidad que conlleva la identificación del referente exacto y la traducción al español, cuando se requiere. Ante esta realidad, intentaremos recurrir a otros criterios que puedan permitirnos establecer objetivamente las equivalencias del on en español. En este sentido, nos referiremos a esta noción a la que alude M. Grévisse, en la descripción del on: lo determinado frente a lo indeterminado, aunque, a priori, estos términos parecen algo ambiguos.

Según la RAE, la palabra determinado significa: lo que hace referencia a entidades identificables por los locutores. Esta misma definición está recogida en M. Grévisse, quien presenta el on como un nominal cuyo referente es una persona determinada, aunque también alude a persona o personas indeterminadas. Esta definición alude a características semánticas pero no gramaticales. En el nivel gramatical, la norma establece que on pertenece al paradigma de los pronombres indefinidos. Es, concretamente, un pronombre indefinido invariable. Al hilo de esta categorización, se puede comprobar que on denota persona, aunque no alude directamente a un individuo o a una referencia determinada, aunque como pronombre desempeña lógicamente la misma función de sujeto como cualquier otro pronombre. Por este motivo, como señalamos (ver ejemplos anteriores), tiene la posibilidad de permutar con yo, tú, él, etc. Pero, siendo on un indefinido con valor indeterminado, entendemos que el argumento gramatical no puede por sí solo validar la permutación con otros pronombres que pueden considerarse definidos y determinados como el je (yo), tu (tú), etc. 


\section{Determinación e indeterminación}

De acuerdo con M. Grévisse (1994), el on puede permutar con un pronombre "definido" como: je (yo), tu (tú), il (él), etc., cuando designa a un sujeto determinado. Sin embargo, no indica las condiciones que determinan la representación del referente. Además, aun cuando se admite que on designa a una persona determinada, puede alternar con cualquiera con los pronombres personales que acabamos de indicar. En consecuencia, resulta ambiguo y asimismo no puede considerarse un criterio objetivo y pertinente. Veamos el ejemplo siguiente:

"Oui, je sais on (il/elle) me l'a raconté hier" (Miguel Borda, p.40). En español, corresponde a: "Sí, lo sé, me lo dijeron ayer". En esta oración, el on permuta perfectamente con los pronombres él/ella. Estos últimos pueden aportar alguna precisión sobre el sujeto y, además, no modifican el sentido de la oración. Entonces, pudiendo emplear estos pronombres alternativos para referirse objetivamente a la persona a la que el locutor alude, ¿por qué siembra tantísima duda y confusión emplear la forma on? Al comprobar los límites de la noción de la determinación-indeterminación, intentaremos, a continuación, buscar la clave del uso predominante del on mediante otros criterios que tal vez puedan indicar, al mismo tiempo, unas pautas sobre las posibles equivalencias en español.

\section{El criterio pragmático}

Este enfoque atañe a la lógica conversacional ${ }^{12}$ en referencia a los componentes discursivos y extralingüísticos que participan en la elaboración del mensaje. Es pragmático ya que trata la descripción de hechos lingüísticos que exceden los límites de la morfosintaxis y la semántica del on. Para que resulte explícito, tomaremos este pronombre tal y como se manifiesta en el lenguaje, según la perspectiva desde la que los locutores lo usan. Esto implica la relevancia de "los factores extralingüísticos tales como el emisor, el destinatario, la intención comunicativa, el contexto verbal y el conocimiento del mundo, etc." (Escandell, 1993, p.1315). En este sentido, entendemos que la búsqueda de los equivalentes on en español pasa por la identificación del referente, pero habiendo fracasado en este intento con los criterios anteriores examinaremos en qué medida el enfoque pragmático podría posibilitar este proceso. Para llevar a cabo este último análisis, recurriremos a las siguientes oraciones (a y b) de Miguel Borda (ibidem, pp.139-140) y otras (c y d) de Espasa Calpe (2008, p.57-59).

\section{1. "On danse tango en Argentine."}

1a - Bailamos tango en Argentina.

$1 \mathrm{~b}$ - Bailan tango en Argentina.

1c - Se baila tango en Argentina.

El pronombre on, tiene un valor incluyente en 1a y en $1 b$ es excluyente.

2. "On emporte les skis ou on en louera sur place?"

$2 \mathrm{a}-$ ¿Nos llevamos los esquíes o los alquilaremos en el propio sitio? $2 \mathrm{~b}-$ ¿Lleváis los esquíes o los alquilaréis en el propio sitio? $2 \mathrm{c}-$ ¿Te llevas los esquíes o los alquilarás en el propio sitio? 
El pronombre on es incluyente en 1a, 2 a y 2 b, pero es excluyente e indeterminado en $1 b, 1 c, 2 b$ y 2c. A continuación, veamos los siguientes ejemplos (3 y 4):

\section{3. "Jeannette et moi, on est revenues en taxi."}

3a - Jeannette y yo volvimos en taxi.

Los sujetos Jeannette y yo son antecedentes del pronombre on. Esto es, el on desempeña la misma función de sujeto al igual que los primeros. En consecuencia, son los referentes de este pronombre que tiene en este caso un valor enfático.

4. "Alors, on est fière, on ne dit plus bonjour aux amis?"

$4 \mathrm{a}-$ ¿Pues, te sientes orgulloso, ya no das los buenos días a los amigos? $4 \mathrm{~b}-$ ¿Pues, se siente usted orgulloso, ya no da los buenos días a sus amigos?

El enunciado 4 puede admitir dos posibles interpretaciones que denotan, a su vez, dos referentes.

Siguiendo la primera interpretación, el on designa a un referente claramente determinado, por deducción lógica: un amigo. Esta información se desprende de la relación entre el enunciado y los interlocutores. Uno (emisor) increpa sutilmente al otro (destinatario) por su conducta, preguntándole si se siente orgulloso por no saludar a los demás amigos. En consecuencia, el trato con tú se fundamenta en la interpretación que ofrece el propio enunciado sobre los protagonistas. Si no hubiera una relación de amistad, no tendría sentido que se preguntara a un desconocido por qué no saluda a otros.
Siguiendo la segunda interpretación, el on mediante esta pregunta puede resultar bastante genérico e indeterminado, es decir, sin referencia concreta. En este caso, el equivalente en español corresponde a uno (cualquier persona), tal y como se aprecia en el enunciado $4 \mathrm{~b}$.

En general, se observa que excepto el ejemplo $\mathrm{c} 1^{13}$, casi todas las oraciones 1, 2 y 4 admiten por lo menos dos equivalencias o traducciones posibles al español. Y, en cada caso, on tiene un valor incluyente o excluyente $\mathrm{y}$, también, tiene un valor tanto determinado como indeterminado. En conclusión, esta realidad da a entender que a pesar de que la interpretación adecuada del enunciado pueda proporcionar unas pautas sobre el referente del on, no permite descartar o eliminar sistemáticamente otras alternativas. Sigue habiendo la probabilidad de que aluda a otros referentes. Asimismo, mientras el uso de on en el enunciado pueda denotar más de una referencia probable, opinamos que los criterios morfosintácticos y semánticos no permiten eludir los errores que se plantean en término de equivalentes gramaticales en español. Pues, si fuera el caso, el análisis llevaría a una sola traducción posible. Sin embargo, a pesar de sus límites, hay que destacar la importancia del enunciado por ofrecer unas informaciones convencionales (gramaticales) que pueden, en alguna medida, contribuir a determinar o a delimitar el referente, así como las equivalencias de on en español.

De hecho, el enunciado es sencillamente una combinación de formas gramaticales y semánticas con validez universal, esto es, en cualquier ámbito lingüístico. No proporciona toda la información necesaria para determinar el 
referente, ni la equivalencia exacta de on en el español. Por lo tanto, se examinará este elemento gramatical en un nivel superior, esto es, la unidad supraoracional o el texto. Asimismo, el texto, también considerado como discurso, implica necesariamente las circunstancias de su elaboración. Se trata del contexto que ocupará nuestro interés a continuación.

\section{Contexto y pragmática}

La relación que se establece entre los componentes lingüísticos y extralingüísticos, es decir: enunciado-contexto-interlocutores, es un principio fundamental de la pragmática como área que se ocupa del análisis e interpretación de los enunciados. Según V. Escandell, el contexto ${ }^{14}$ cobra especial relevancia en este proceso, ya que contribuye significativamente a hacer explícito el mensaje o la información que se transmite a los hablantes o interlocutores. Es un concepto amplio definible como "las circunstancias de la realidad que se desarrolla un enunciado" (Conde Frías, 2001, p.5).

Ya apuntamos que la unidad supraoracional se corresponde con el texto, el cual deriva necesariamente de un contexto en concreto. A continuación, propondremos unos ejemplos que indican el contexto en que se desarrolla el acto comunicativo. Para no extendernos, consistirá sencillamente en volver a utilizar las oraciones anteriores (1, 2 y 4), añadiendo a cada una un apéndice o una proposición donde se expresa un proceso acompañado de otras valencias.

1. "On danse tango en Argentine, lorsque nous y passons les vacances." 1aa - Bailamos tango en Argentina, cuando vamos a pasar las vacaciones.

Este texto lleva unos elementos gramaticales, lexicales y contextuales interesantes, además de ofrecer alguna información sobre los protagonistas o interlocutores. a) El indefinido on aparece sustituido por el pronombre nous en la proposición: "cuando vamos a pasar las vacaciones". Ambos desempeñan la función de sujeto. Al ser este último incluyente y determinado (tú + yo, vosotros/as o él/ellos/as + yo = nosotros), el on adquiere lógicamente estas mismas propiedades semánticas. b) El análisis sémico de la unidad léxica vacaciones indica los semas: descanso, libertad, entretenimiento, etc. Además, la experiencia general, en término de costumbres, nos enseña que las vacaciones son un período para disfrutar del tiempo y, por lo tanto, para estar a gusto; se suele compartir entre amigos o familiares que mantienen cierta proximidad o intimidad entre ellos.

Al final, como se comprueba, la identificación del referente de on y su equivalencia en español, se apoya en la interpretación de la suma de elementos gramaticales, semánticos, contextuales, socioculturales, etc. A continuación, examinaremos el texto 2.

2. "Bon séjour messieurs! ¿On emporte les skis ou en louera sur place?"

2aa - ¡Que tengan una buena estancia, señores! ¿Se llevan ustedes los esquíes o los alquilarán en el propio sitio?

El enunciado informa sobre una despedida dirigida a personas que van a esquiar. El contexto sociocultural indica 
el deporte de esquí. El contexto discursivo alude a dos clases de interlocutores. Por un lado, el que (supuestamente, un criado) se despide y, por otro lado, las personas (supuestamente, los dueños) de quienes este último se despide.

También, se puede interpretar que unos clientes estén en el hotel de una estación de esquí y, a la hora de subir a la pista, el recepcionista se dirige a ellos y pregunta si llevan los esquíes o los alquilarán en el propio sitio. En cualquier caso, el contexto permite descartar cualquier otra forma de trato hacia el referente de on. Permuta lógicamente con el pronombre ustedes e indica, en este caso, cortesía o consideración y distanciamiento. A continuación, examinaremos el texto 3 .

3. "Alors, on est fière, on ne dit plus bonjour aux amis? Le bizutage est une tradition universitaire."

3aa - ¿Pues, te sientes orgulloso, ya no das los buenos días a los amigos? La novatada es una costumbre universitaria.

Se comprueba que el on es sustituido en español por la 2. ${ }^{a}$ persona del singular. La elección de este pronombre como referente se debe a la interpretación que proporcionan unas unidades lexicales del texto y del contexto. En concreto, se trata de una novatada en una universidad. Los interlocutores o protagonistas, es decir, la víctima y los autores de la novatada son compañeros.

Aparecen unos elementos del cotexto: amigos, novatada, etc. y otros del contexto: universidad, tradición, etc., que contribuyen a la interpretación o la designación del referente del on. Asimismo, nos apoyamos en la noción de compañerismo y en el estatus social de los interlocutores (universitarios), como criterios sociológicos relevantes para determinar el uso del pronombre de la 2. ${ }^{a}$ persona del español como equivalencia del on francés.

\section{Uno, se + verbo + tercera persona del plural}

Son las formas propias del pronombre indefinido en español que equivalen al on francés. Pero tienen cada una sus propiedades particulares.

\subsection{Uno y sus variantes}

El cuantificador uno puede experimentar diversas categorizaciones gramaticales -sustantivo, adjetivo, etc.- pero nos interesa su forma pronominal. Admite variación de género y número -uno, una, unos, unas- y puede ser pronombre indefinido: unas veces, cuando designa vagamente a una(s) persona(s) y, otras veces, es pronombre personal cuando designa a un referente determinado.

\subsection{Uno, con referente genérico o indeterminado}

La RAE considera "el uso de uno o una como pronombre personal indefinido". Asimismo, cuando remite al carácter genérico de persona, uno viene a ser un yo genérico. Por un lado, el emisor relata su experiencia sin aludir a elementos referenciales concretos. En tal caso, se considera que el pronombre ha perdido su valor deíctico personal. Y, por otro lado, puede que el emisor se refiera a una experiencia de carácter general, como ocurre en las máximas proverbiales. A continuación, hemos 
elaborado un corpus para ilustrar estas propiedades. Veamos estos ejemplos:

a. A mi edad, uno no puede valerse por sí mismo.

b. Se aprecia mejor la felicidad cuando uno la ha perdido.

c. A uno se le antoja siempre lo que no debe.

d. Uno no puede estar tumbado en la cama y esperar que le llegue la suerte.

En los enunciados a, b y c se emplea el pronombre uno con valor indefinido e incluyente. Abarca a cualquier persona o cualquier persona más al propio emisor (yo). En los ejemplos anteriores designa a las personas que, tal vez, hayan experimentado las mismas circunstancias que el emisor, y este último generaliza su experiencia. En el enunciado c, el emisor declara que la envidia es causa de desgracia para cualquier persona. Por lo tanto, uno representa a un sujeto genérico en una oración con valor sentencioso o proverbial.

\subsection{Yo y tú, variantes de uso de uno}

En la mayoría de manuales de gramática, uno suele describirse como un pronombre indefinido, es decir, sin referencia concreta. Sin embargo, se comprueba que puede usarse con una focalización sobre el propio emisor (yo) o sobre la 2. ${ }^{a}$ persona (tú), cuando alterna con estos pronombres en ciertas situaciones comunicativas. Asimismo, Kristel Guirado (2011) señala que se emplea a modo de encubrimiento de estos pronombres (1. ${ }^{\mathrm{a}}$ y $2 .^{\mathrm{a}}$ personas) con los que puede llegar a confundirse. A continuación, se intentará evidenciar este comportamiento sobre este corpus sociolingüístico empírico, registrado en ciertas situaciones comunicativas en Madrid. Ejemplos:

a. Sin mis nietos, uno no puede estar a gusto en esta casa.

b. Carlos, por favor, uno no puede estar siempre tumbado en la cama todo el día.

Si estas frases estuvieran enmarcadas en una situación comunicativa determinada, uno podría ser sustituido por los pronombres yo o tú, respectivamente, en las oraciones a y b. Por consiguiente, en nuestra opinión, el contexto aparece como un factor relevante en el análisis de las propiedades semánticas de uno. De hecho, "el verdadero alcance semántico, sólo se desprende del contexto. Los ejemplos truncados y a menudo adaptados que aparecen en los manuales y gramáticas, y cuyo contexto desconocen o dan, por supuesto, los mismos comentaristas, no pueden dar cuenta de ello y esconden o alteran el pronombre [...] Además un exceso de primeras personas en un texto puede parecer fastidioso, molesto o irritante y en tal caso, se trata de una variación estilística" (De Kock, p.160).

El papel del contexto en la interpretación y la explicación de cualquier enunciado es indiscutible, pero se debe inscribir en el marco general de la pragmática; entendemos que este campo ofrece todas las herramientas idóneas para llevar a cabo esta tarea con eficiencia, tal y como venimos planteando. Volviendo a la aproximación de K. Guirado, podemos afirmar que uno, al igual que el on, se caracteriza por su variabilidad, al experimentar alternancias con los pronombres yo o tú. Y, en este caso, cumple una función retórica o estilística. Pero, a pesar de 
esta dualidad, uno no deja de ser un pronombre indefinido. Unas veces, designa vagamente a personas; otras veces, cuando se usa en un contexto, puede aludir a determinados referentes sin perder, por ello, su carácter genérico.

\section{a. Se + verbo}

Este equivalente del on es una forma particular y propia del español frente a las lenguas con las que está emparentado, como el francés en este caso. Tiene valor genérico e indeterminado, como señalamos en los ejemplos 1b y 1c. Pero habría que señalar que, a pesar de que esta construcción coincide con la forma reflexiva del verbo, no hay que confundirlas. Volvamos a este ejemplo:

Juan se despierta, se ducha y se acuesta.

En este caso, se + verbo corresponde a la forma reflexiva. La forma indefinida estaría representada mediante la sustitución del nombre Juan por uno, generalmente antepuesto a la forma reflexiva. Por ejemplo:

Uno se despierta, se ducha y se acuesta - "On se lève, on se lave et on se couche."

Se observa que en francés se repite el pronombre delante de cada uno de los verbos. Pero esta repetición del pronombre es lo gramaticalmente correcto, y no implica ninguna intención estilística por parte del locutor.

\section{b. La 3. ${ }^{\text {a }}$ persona del plural}

La 3. ${ }^{a}$ persona del plural empleada como indefinido representa también una particularidad del español. Como hemos señalado en el ejemplo 1a, es equivalente del on y, en este caso, es genérico y excluyente. Vean el ejemplo 1a:

\section{Bailan tango en Argentina.}

Se observará que, al ser el español un sistema "pro drop", no requiere el uso de un sujeto sintáctico expreso, salvo cuando el contexto es confuso o cuando se quiere expresar un énfasis. Pero también, el uso de la 3. ${ }^{a}$ persona como indefinido puede acarrear ciertas confusiones, sobre todo en frases sueltas o desvinculadas de algún contexto en concreto. Por este motivo, sostenemos que, en general, la representación del referente de on y los correspondientes equivalentes en español es un proceso que se debe realizar mediante previo análisis gramatical y pragmático.

\section{Funciones del on según los registros}

En general, se comprueba su uso tanto en los registros formales como informales. Pero el registro en el que se emplea influye necesariamente en la interpretación y la identificación del referente.

\subsection{On, en el registro formal}

Se suele usar en el lenguaje académico y literario con matices estilísticos (M. Grévisse, 1994) cuando el locutor desea expresar unas veces discreción, modestia y cortesía; otras veces, ironía y menosprecio, etc. Asimismo, siendo un recurso estilístico, el on se usa para ocultar los pronombres je (yo), tu (tú), nous (nosotros/as), vous (vosotros/as), il(s) (él/ellos), elle(s) (ella(s). Ejemplos: a) "On [je] a cherché à obtenir des 
renseignements" (ibidem, p.1101) Hemos [he] intentado obtener informaciones. En esta frase, on tiene un matiz de discreción. En español, también es frecuente emplear la 1. ${ }^{a}$ persona del plural en algunas frases que expresan retóricamente ironía e incluso sarcasmo. Por ejemplo, una persona con gripe estornuda y otra comenta: ¡Estamos buenos! La 1. a persona puede ser sustituida por la 2. ${ }^{a}$ del singular, haciendo referencia directa al enfermo. Sin embargo, mediante la 1 . $^{\mathrm{a}}$ persona se rehúsa esta alusión por cortesía. Pero, al trasladar esta misma frase a otros registros, es muy probable que se pierda este matiz.

\subsection{On, en el registro informal}

Este pronombre es de uso corriente en el lenguaje informal y familiar. Compite generalmente con los demás pronombres (yo, tú, él, etc.) y en especial con el de la 1. ${ }^{a}$ persona del plural: nous (nosotros), etc., sin intención de expresar algún matiz particular. Por ejemplo: On [nous] joue au basket (M. Borda, p.140) - Jugamos al baloncesto. Este uso es muy habitual entre amigos y familiares. Recuerden que cuando on se emplea en el lenguaje coloquial suele traducirse al español mediante la 1. ${ }^{a}$ persona del plural (nosotros).

\section{Expresiones fraseológicas con on y sus equivalencias en español}

En este apartado, se proponen unas expresiones y refranes que llevan el pronombre on. Esta muestra indica el uso abundante de este pronombre en francés. Se emplea con muchísima frecuencia, en expresiones idiomáticas y en las máximas. En el lenguaje coloquial puede decirse que se abusa particularmente de su uso. Intentaremos traducirlas al español.

1. Qu'en-dira-t-on - ¿Qué dirán?

2. On y va (locución) - a) vamos, vámonos; b) adelante.

3. On ne sait jamais, o Sait-on jamais (expresión fija) - Nunca se sabe.

4. On dit que (locución) - dicen que, se dice que.

5. On reconnaît l'arbre à ses fruits (dicho popular) - Se reconoce al árbol por sus frutos.

6. Ondit - rumores.

7. On ne fait pas des omelettes sans casser des œufs (dicho popular) No hay bien que se obtenga sin sacrificios; para hacer tortilla hay que romper los huevos.

8. On n'est jamais mieux que chez soi - No hay nada como el hogar

9. On a souvent besoin d'un plus petit que soi (Expresión de Lafontaine) - Todas las criaturas suelen resultar útiles.

Las expresiones 1, 2, 3, 4 y 5 admiten las siguientes formas del indefinido español: 3. a persona del plural, se + verbo, como equivalencias formalmente establecidas del on, aunque también resultan correctos otros recursos, como ocurre en las expresiones 6, 7, 8 y 9. Por consiguiente, las coincidencias del on con estas formas del indefinido español pueden considerarse hechos casuales. Así, siendo cada expresión un dicho propio de la lengua de origen, no hay reglas que establezcan equivalencias fijas en otros idiomas y, por lo tanto, conviene emplear construcciones que reproducen la idea que se desea transmitir. 
Asimismo, se observa que, para trasladar las demás expresiones $6,7,8$ y 9 al español, se tuvo que recurrir tan solo a unas perífrasis en las que se refleja el carácter genérico y axiomático del dicho, tal y como se da en francés.

\section{Aproximación didáctica}

A los fines didácticos, sería conveniente replantear los conocimientos que tenemos sobre este indefinido on. En primer lugar, entendemos que las variaciones que experimenta, en determinados contextos, lo convierten en un pronombre híbrido y así debería considerarse dentro de la categoría de los indefinidos. En otros términos, por su carácter opaco, al referirse de forma imprecisa o indeterminada a personas, y también concreto al encubrir otros pronombres (yo, tú, él, etc.), lo denominaremos: pronombre indefinido híbrido. En segundo lugar, siguiendo los análisis anteriores (6.1.2), se comprueba que el elemento gramatical equivalente en español es uno, aunque esto no significa que haya una correspondencia sistemática entre ellos en el nivel sintáctico, es decir, que no siempre se puede traducir on por uno.

En consecuencia, con base en estos comportamientos, se podría proponer la siguiente aproximación teórica y metodológica:

a. Exponer las propiedades formales y funcionales tanto en francés como en español.

b. Señalar las diferencias que conlleva en ambas lenguas.

c. Destacar la importancia de los factores pragmáticos.
Ya apuntamos que al basarse en enunciados sueltos o desprendidos de cualquier contexto, las normas de uso de on y las correspondientes equivalencias en español, tal y como proponen los manuales, resultan útiles pero insuficientes o demasiado formales para aprehender este indefinido. Su carácter versátil dificulta, a menudo, el reconocimiento del referente aludido. Asimismo, resulta muy embarazoso proponer una o la forma correspondiente en el español, que es un sistema particular, con diversos recursos gramaticales propios mediante los que se representa este indefinido. Por ello, este último paso (c) es el más significativo, al ser el proceso por el que se identifica el referente del on en el texto o en el acto comunicativo.

\section{Conclusión}

Al finalizar este estudio, podríamos retener que los pronombres indefinidos analizados se caracterizan por su contenido impreciso e indeterminado tal y como lo enseña la gramática tradicional. Asimismo, entendemos que el pronombre on y las formas correspondientes uno, se + verbo, etc., han de ser considerados como indefinidos híbridos, pues son tan variables como difíciles de aprehender por su capacidad de aludir a referentes diversos que no siempre resultan explícitos en el lenguaje. Por esto mismo, los consideramos ambiguos y carentes de la focalización personal, sobre todo cuando se extraen del enunciado o del texto.

Sin embargo, en español, cada una de las diversas formas: uno, se + verbo, 3. ${ }^{\text {a }}$ persona plural, ofrece cierta perspectiva referencial, lo cual corresponde a cierto grado de focalización del referente 
específicamente aludido al basarse en los criterios de inclusión o de exclusión del emisor en el proceso, junto con el contexto que permite relacionarlos o sustituirlos por otros pronombres personales (yo, tú, él, etc.).

Respecto a ello, ya se ha podido comprobar que los criterios formales y semánticos son poco rigurosos y pertinentes, porque aportan más problemas que soluciones sobre la identificación de la equivalencia adecuada entre el on y las correspondientes formas del español. Además, como señalamos, por su carácter híbrido, el análisis segmentado de enunciados aislados no posibilita el tratamiento holístico del pronombre on, que se presenta como una unidad funcional ambigua cuyas propiedades gramaticales así como sus equivalencias en español deberían ser consideradas, más bien, dentro de la estructura supraoracional, o sea, en el discurso entendido como texto.

En definitiva, resulta que los errores que cometen francófonos $\mathrm{y}$, particularmente, la mayoría de nuestros alumnos en la enseñanza-aprendizaje del español como L2 proceden de la influencia del sustrato lingüístico nativo o las interferencias derivadas del paralelismo que suelen establecer entre estas lenguas. Asimismo, las confusiones observadas sobre el uso o el estudio de los indefinidos en ambas lenguas podrían tener el mismo origen. Para remediarlos, se ha demostrado la eficiencia de la aproximación pragmática como el recurso teórico adecuado cuando toca determinar el referente del on, así como sus equivalencias correspondientes en el español, al margen de las instrucciones convencionales que propone la mayoría de manuales.

\section{Notas}

1. Son estudiantes francófonos del Departamento de Lengua Española de la Universidad FHB de Abiyán (Costa de Marfil), y se clasifican en los niveles $A$ y B del MCER.

2. Ver Uriel Wenreich (1956).

3. Ídem, M. Duviols y J. Villégier (1964).

4. Algunos datos del corpus fueron recogidos y contrastados en el entorno sociolingüístico madrileño, durante unas estancias en esta ciudad.

5. Antonio Quilis (1979), La influencia del francés en el habla de niños españoles, Boletín AEPE, N. ${ }^{\circ} 21$, pp. 1-87

6. Ibidem.

7. Joshua Fishman (1970), Bilingual education in a sociolinguistic perspective, pp. 1-12; ver M. Siguán (1982), Lenguas y educación en el ámbito del estado español, pp. 3-317.

8. Alguien, nadie, nada, algo etc., correspondiendo en francés a: quelqu'un, personne o nul, rien, quelque chose, etc. (ver La grammaire espagnole, p.117)

9. Ver Le bon usage, "on range sous le nom de pronom indefini des mots variés indiquant, soit une quantité chiffrée (par ex. plusieurs) soit une indication imprécise (par ex., quelque chose) ou même une indication d'identité (un tel)".

10. Notemos que la mayoría de los locutores francófonos, como es el caso de los alumnos de Costa de Marfil, tienen el francés como L1 pero hablan también, por lo menos, una lengua nativa, su verdadera lengua materna que suele interferir en su conocimiento del francés. En consecuencia, su nivel de competencia aparece, a menudo, relativamente limitado por este proceso que impide el dominio de ciertos aspectos gramaticales. 
11. Recordemos que la forma indefinida se + verbo $=$ on, se confunde con los verbos reflexivos. Por ejemplo: Jean se lève, s'habille et se couche (M. Borda, p.140) - Juan se levanta, se viste y se acuesta.

12. Ver P. Grice (1975).

13. En este ejemplo, on es pronombre sujeto y sustituye a Jeannette y yo. Por lo tanto, el referente está claramente indicado en el propio enunciado.

14. Frías Conde (ibidem, pp.6-7) destaca tres factores contextuales: a) social (elementos idiomáticos que reflejan la idiosincrasia de una comunidad), b) situacional (informaciones de la conversación), c) lingüístico o cotexto (todo material que precede al enunciado).

\section{Bibliografía}

Borda Lapedie, Juan Miguel (2013), Manuel de français élémentaire, (FLE, A1), Madrid, Cevediciones.

Borra, Joke (2010), La impersonalidad semántica de on y sus equivalencias en español, Universiteit Gent, Academiejaar.

Bouzet, Jean (1974), La grammaire espagnole, París, Les Procédés Dorels.

Cayo Franco, Martin (1990), "Interferencias lingüísticas en el aprendizaje del español por estudiantes francófonos", Revista de investigación y de innovación en la clase de idiomas, Universidad de Alcalá, N. ${ }^{\circ}$ 21, pp. 117-124.

Company, Concepción (2005), "La formación de las lenguas romances", Introducción a la cultura medieval, A. González y María Antonia Maja (Ed.), Facultad de Filosofía y Letras, UNAM, México, pp. 111-125.
Conde Frías, Xavier (2001), "Introducción a la pragmática", Revista Philologica Romanica, pp. 3-35.

De Kock, Josse (1998), "Norma, libertad y probabilidad: ocho soluciones del español", Ediciones Universidad de Salamanca, pp.155-165.

Duviols, Marcel y Villegier, Jean (1964), Grammaire espagnole, París, Hatier.

Espasa Calpe (2008), La gramática francesa, Madrid.

Grice, Paul (1975), "Logic and conversation", Syntax and Semantics, Vol. 3, pp.41-58

Fishmman, Joshua (1970), "Bilingual education in a sociolinguistic perspective", Fourth annual TESOL Convention, pp. 1-12

Guirado, Kristel (2011), "La alternancia tú-uno en el habla de Caracas", Revista Asociación de Lingüistica y Filología de América Latina, volumen 26, Caracas, Universidad Central de Venezuela, pp.26-54.

Illera, Alicia (2014), "Linguistique contrastive, linguistique comparée, linguistique tout court", in $E d$. UNED, pp. 22-35

Lado, Robert (1968), "Contrastive linguistics in a mentalistic language learning", Monograph series on language and linguistics, Ed. James E. Alatis, Georgetown, pp. 135-236.

Landragin, Fréderic y Tanguy, N. (2014), "Référence et coréférence du pronom on", Langages, Larousse, pp. 99-115.

Mendivíl, J. Luis (2009), Origen, evolución y diversidad de las lenguas, Frankfurt, Ed. Peter Lang.

Weinreich, Uriel (1956), Languages in Contact, The Hague, Mouton. 